\title{
A phase II study of biweekly oxaliplatin plus infusional 5-fluorouracil and folinic acid (FOLFOX-4) as first-line treatment of advanced gastric cancer patients
}

\section{F De Vita*,', M Orditura', E Matano ${ }^{2}$, R Bianco², C Carlomagno², S Infusino², V Damiano², E Simeone², MR Diadema', E Lieto ${ }^{3}$, P Castellano ${ }^{3}$, S Pepe ${ }^{2}$, S De Placido ${ }^{2}$, G Galizia ${ }^{3}$, N Di Martino ${ }^{4}$, F Ciardiello', G Catalano' and AR Bianco ${ }^{2}$}

'Division of Medical Oncology, 'F Magrassi \& A Lanzara' Department of Clinical and Experimental Medicine, Second University of Naples School of Medicine, Naples, Italy; 'Division of Medical Oncology, Department of Molecular and Clinical Endocrinology and Oncology, 'Federico II' University of Naples School of Medicine, Naples, Italy; ${ }^{\prime \prime l}$ Division of General Surgery, 'F Magrassi \& A Lanzara' Department of Clinical and Experimental Medicine, Second University of Naples School of Medicine, Naples, Italy; ${ }^{4}$ VII Division of General Surgery, 'F Magrassi \& A Lanzara' Department of Clinical and Experimental Medicine, Second University of Naples School of Medicine, Naples, Italy

The aim of the study was to assess the toxicity and the clinical activity of biweekly oxaliplatin in combination with infusional 5-fluorouracil (5-FU) and folinic acid (FA) administered every 2 weeks (FOLFOX-4 regimen) in patients with advanced gastric cancer (AGC). A total of 61 previously untreated AGC patients were treated with oxaliplatin $85 \mathrm{mg} \mathrm{m}^{-2}$ on day I, FA $200 \mathrm{mg} \mathrm{m}^{-2}$ as a $2 \mathrm{~h}$ infusion followed by bolus 5-FU $400 \mathrm{mg} \mathrm{m}^{-2}$ and a $22 \mathrm{~h}$ infusion of 5-FU $600 \mathrm{mg} \mathrm{m}^{-2}$, repeated for 2 consecutive days every 2 weeks. All patients were assessable for toxicity and response to treatment. Four (7\%) complete responses and 19 partial responses were observed (overall response rate, 38\%). Stable disease was observed in 22 (36\%) patients, with progressive disease in the other six ( I0\%) patients. Median time to progression (TTP) and median overall survival (OS) were 7.1 and I I.2 months, respectively. National Cancer Institute Common Toxicity Criteria grade 3 and 4 haematologic toxicities were neutropenia, anaemia and thrombocytopenia in 36, 10 and 5\% of the patients, respectively. Grade 3 peripheral neuropathy was recorded in three (5\%) patients. FOLFOX-4 is an active and well-tolerated chemotherapy. Response rate (RR), TTP and OS were comparable with those of other oxaliplatin-based regimens, suggesting a role for this combination in gastric cancer.

British Journal of Cancer (2005) 92, I644- 1649. doi:I0.1038/sj.bjc.6602573 www.bjcancer.com

Published online 26 April 2005

(C) 2005 Cancer Research UK

Keywords: advanced gastric cancer; chemotherapy; 5-fluorouracil; oxaliplatin

Despite a decreasing trend in its incidence, gastric cancer remains the second most common cause of cancer-related death (Parkin, 1998); furthermore, there was a change in the site of origin within the stomach, with a rising incidence of cancer of cardia and gastroesophageal junction (Blot et al, 1991). Advanced gastric cancer (AGC) remains incurable with a median survival of 6-9 months (Alberts et al, 2003). However, in randomised trials, chemotherapy was demonstrated to result in both a significant survival advantage and an improved quality of life when compared to best supportive care (Murad et al, 1993; Pyrhonen et al, 1995; Glimelius et al, 1997). 5-Fluorouracil (5-FU) remains the most extensively studied single agent, and continuous intravenous infusion is frequently used in combination chemotherapy regimens (Alberts et al, 2003). The association of epirubicin, cisplatin

* Correspondence: Dr F De Vita, Division of Medical Oncology, 'F Magrassi \& A Lanzara' Department of Clinical and Experimental Medicine, Second University of Naples School of Medicine, c/o II Policlinico, Via S Pansini, 5, 8013I Naples, Italy;

E-mail: fernandodevita@yahoo.it

Revised 5 January 2005; accepted II March 2005; published online 26 April 2005 and 5-FU in continuous infusion, also known as ECF regimen, showed an impressive activity in a phase II trial, with $12 \%$ complete responses (CR). Compared with FAMTX in a phase III randomised trial, ECF obtained a higher response rate, a superior median time to progression (TTP) and a better overall survival (OS) (Webb et al, 1997). Because of these results, ECF was considered as the European standard treatment. Several platinum analogues have been developed with the aim of improving the efficacy and tolerability of cisplatin. Recently, oxaliplatin, a thirdgeneration platinum compound with the 1,2-diaminocyclohexane $(\mathrm{DACH})$ carrier ligand, has entered the clinical practice, showing a different toxicity profile, with neurotoxicity being the doselimiting toxicity (Extra et al, 1990; Raymond et al, 1998). Oxaliplatin showed additive or synergistic activity when associated to 5-FU, even in 5-FU-resistant cell lines (Becouarn et al, 2001). It has been registered worldwide for the treatment of advanced colorectal cancer, where, in association with 5-FU, it was reported to yield a response rate of 36-58\% (Levi et al, 1992; Levi et al, 1994; De Gramont et al, 2000). In in vitro studies, oxaliplatin was demonstrated to inhibit the growth of several gastric cancer cell lines (Eriguchi et al, 2003). In a phase II study involving previously CDDP-treated patients with AGC, a bimonthly association of 
oxaliplatin, 5-FU and leucovorin was associated with a $26 \% \mathrm{RR}$ and an acceptable toxicity profile (Kim et al, 2003). Furthermore, in a phase II study, a biweekly FOLFOX-6 regimen (oxaliplatin $100 \mathrm{mg} \mathrm{m}^{-2}$, FA $400 \mathrm{mg} \mathrm{m}^{-2}$ followed by bolus 5 -FU $400 \mathrm{mg} \mathrm{m}^{-2}$ and a $46 \mathrm{~h}$ continuous infusion of $5-\mathrm{FU} 3000 \mathrm{mg} \mathrm{m}^{-2}$ ) was demonstrated to be an active and safe treatment in 51 chemotherapy-naive patients with AGC (Louvet et al, 2002). These results were recently extended by a multicentre phase II study in 41 AGC patients treated with a modified FOLFOX schedule (oxaliplatin $85 \mathrm{mg} \mathrm{m}^{-2}$, FA $500 \mathrm{mg} \mathrm{m}^{-2}$ followed by 5 -FU $2600 \mathrm{mg} \mathrm{m}^{-2}$ as a $24 \mathrm{~h}$ continuous infusion every 2 weeks) (AlBatran et al, 2004). Here, we report the results of a multicentre phase II trial aimed at determining the efficacy and safety of a FOLFOX-4 regimen as first-line treatment in 61 AGC patients.

\section{PATIENTS AND METHODS}

\section{Eligibility}

Patients with histologically proven unresectable locally advanced or metastatic gastric cancer were considered eligible for the study if they met all of the following criteria: measurable disease; cytologically or histologically proven single metastatic lesion as the only manifestation of the disease; aged $>18$ and $<75$ years; ECOG PS $<2$; life expectancy $>3$ months; adequate bone marrow, hepatic and renal function; no prior palliative chemotherapy; written informed consent before enrolment in the study. Previous adjuvant chemotherapy was allowed if more than 6 months had elapsed between the end of adjuvant therapy and first relapse.

\section{Treatment and toxicity assessment}

Chemotherapy consisted of oxaliplatin $85 \mathrm{mg} \mathrm{m}^{-2}$ on day 1, FA $200 \mathrm{mg} \mathrm{m}^{-2}$ as a $2 \mathrm{~h}$ infusion followed by bolus 5 -FU $400 \mathrm{mg} \mathrm{m}^{-2}$ and a $22 \mathrm{~h}$ infusion of 5 -FU $600 \mathrm{mg} \mathrm{m}^{-2}$ on days 1 and 2 every 2 weeks. The use of central venous catheters and disposable pumps allowed chemotherapy administration on an outpatient basis. This regimen was administered until progression. Toxicity was assessed before starting and each 2 -week cycle using the National Cancer Institute Common Toxicity Criteria (NCI-CTC), version 1.0, except neurotoxicity. Peripheral sensitive neuropathy was graded according to the following oxaliplatin-specific scale: grade 1, paresthesias/ hypoesthesias of short duration with complete recovery before the next cycle; grade 2, paresthesias/hypoesthesias persisting between two cycles without functional impairment; grade 3, permanent paresthesias/hypoesthesias resulting in functional impairment (Caussanel et al, 1990). Treatment delays and dose modifications were based on the worst adverse effects observed during the previous cycle. Oxaliplatin was reduced to $75 \mathrm{mg} \mathrm{m}^{-2}$ in case of persistent ( $>14$ days) paresthesia or temporary (7-14 day) painful paresthesia or functional impairment. In case of persistent ( $>14$ days) painful paresthesia or functional impairment, oxaliplatin was omitted from the treatment until recovery. Together with reductions in the dose of oxaliplatin, the bolus dose of $5-\mathrm{FU}$ was reduced to $300 \mathrm{mg} \mathrm{m}^{-2}$ and the infusion dose to $500 \mathrm{mg} \mathrm{m}^{-2}$ in the event of grade 3 or 4 neutropenia, thrombocytopenia, diarrhoea, stomatitis or other drug-related adverse effects of grade 3 . Treatment was delayed by up to 3 weeks until the patient recovered from various adverse effects, the neutrophil count exceeded 1500 per cubic millimetre and the platelet count exceeded 100000 per cubic millimetre. In the event of skin toxicity of grade 3 or 4 , only the dose of 5 -FU was reduced.

\section{Study end points}

In 4 weeks before starting chemotherapy, all patients underwent the following studies: physical examination, complete blood cell count, hepatic and renal function tests, chest and abdominal CT scan and an ultrasound endoscopy. Physical examination, hepatorenal function tests and blood counts were performed every cycle. Tumour evaluation was assessed every three cycles according to WHO criteria. Complete response is defined as the disappearance of all known lesions and absence of new lesions; partial response (PR) as a reduction of $50 \%$ or more in the sum of the product of the two-dimensional measures of all known lesions and absence of new lesions; stable disease (SD) as a reduction of $<50 \%$ or an increase $<25 \%$ in the sum of the product of the two-dimensional measures of all known lesions and absence of new lesions; and progressive disease (PD) as an increase of $>25 \%$ in the twodimensional measures of one or more known lesions or as the appearance of at least one new lesion. Treatment was continued until disease progression or unacceptable toxicity occurred or until a patient chose to discontinue treatment. All patients who completed at least three cycles of chemotherapy were deemed assessable for response. All eligible patients were included in the response and survival analysis on an 'intent-to-treat' basis. The primary end point of the study was the overall response rate; secondary end points were toxicity, evaluation of TTP and OS.

\section{Statistical analysis}

The two-stage minimax design for phase II trial of Simon (1989) was adopted, selecting an alpha error $=0.05$ and a beta error $=0.20$. The minimum activity required for this experimental treatment was $30 \%$, while the alternative hypothesis was to obtain a $50 \%$ response rate. Therefore, the accrual had to be stopped if less than six responses were obtained with the first 16 patients. Otherwise, more than 18 responses among a total of 46 patients are required to accept this hypothesis.

Statistical analysis was carried out using the BMDP statistical package (BMDP Statistical Software Inc., Los Angeles, CA, USA). In all analyses, the significance level was specified as $P<0.05$. The Kaplan-Meier method was used to analyse TTP and OS.

\section{RESULTS}

\section{Patient characteristics}

A total of 61 patients were enrolled from March 2001 to June 2003. The characteristics of the patients are summarised in Table 1 . The median age was 64 years and the majority of patients had a Performance Status 1 according to the ECOG scale. A G3 undifferentiated tumour was present in 31 patients (51\%), while a G2 moderately differentiated tumour was observed in 28 patients $(46 \%)$. Metastatic disease was present in the majority of the study population (56 out of 61 patients); liver (38 out of 61 patients, $62 \%$ ) and lymph nodes ( 25 out of 61 patients, $36 \%$ ) were the most common sites of metastases. The median number of organs involved was two (range, $1-4$ ), with 27 patients (44\%) having two organs involved, 10 patients $(16 \%)$ having three organs involved and two patients (3\%) having four organs involved. Prior surgery was performed in 37 out of 61 patients. No patient had received prior radiotherapy, while 10 patients had received adjuvant chemotherapy with 5-FU and folinic acid according to the Machover regimen following radical surgery.

\section{Tumour response}

All 61 patients were evaluable for response to therapy. Major responses were observed in 23 patients (38\%; 95\% CI, 25.8-50.2), with four patients achieving a CR (7\%) and 19 showing a PR (31\%). One CR was pathologically confirmed, since the patient underwent curative surgery after nine cycles of chemotherapy and was alive without evidence of disease as of 31 December 2003. Stable disease was obtained in 22 additional patients (36\%). Progressive disease was observed in 16 patients $(26 \%)$. Therefore, 
Table I Patient characteristics

\begin{tabular}{|c|c|c|}
\hline & No. of patients $(n=6 I)$ & $\%$ \\
\hline \multicolumn{3}{|l|}{ Sex } \\
\hline Male & 38 & 62 \\
\hline Female & 23 & 38 \\
\hline \multicolumn{3}{|l|}{ Age (years) } \\
\hline Median & 64 & \\
\hline Range & $47-75$ & \\
\hline \multicolumn{3}{|l|}{ Histologic diagnosis } \\
\hline Adenocarcinoma & 55 & 90 \\
\hline Signet ring cell carcinoma & 6 & 10 \\
\hline \multicolumn{3}{|l|}{ Grading } \\
\hline 1 & 2 & 3 \\
\hline 2 & 28 & 46 \\
\hline 3 & 31 & 51 \\
\hline \multicolumn{3}{|l|}{ Performance status } \\
\hline 0 & 9 & 15 \\
\hline I & 39 & 64 \\
\hline 2 & 13 & 21 \\
\hline \multicolumn{3}{|l|}{ Adjuvant chemotherapy } \\
\hline Yes & 10 & 16 \\
\hline No & 51 & 84 \\
\hline \multicolumn{3}{|l|}{ Disease status } \\
\hline Locally advanced & 5 & 8 \\
\hline Metastatic & 56 & 92 \\
\hline \multicolumn{3}{|l|}{ No. of organs involved } \\
\hline । & 22 & 36 \\
\hline 2 & 27 & 44 \\
\hline 3 & 10 & 16 \\
\hline$>3$ & 2 & 3 \\
\hline \multicolumn{3}{|l|}{ Organs involved } \\
\hline Liver & 38 & \\
\hline Lung & 12 & \\
\hline Nodes & 25 & \\
\hline Peritoneum & 13 & \\
\hline Pleura & 23 & \\
\hline Ovaries & 1 & \\
\hline Pancreas & 2 & \\
\hline
\end{tabular}

the overall tumour growth control $(\mathrm{CR}+\mathrm{PR}+\mathrm{SD})$ was $74 \%(45$ out of 61 patients).

\section{Survival}

All patients were included in the survival analysis on an intent-totreat basis. The median follow-up was 11.6 months (range, 6.920.3 months). The median TTP was 7.1 months (95\% CI, 5.6-8.7) (Figure 1). At the time of analysis (31 December 2003), 44 patients had died and 17 were alive. The median OS was 11.2 months $(95 \%$ CI, 9.66-14.39). At the time of analysis, two patients who achieved a CR were disease free at 19.9 and 7.6 months of follow-up, respectively. Following documentation of disease progression, 36 out of 61 patients received a second-line docetaxel- or irinotecanbased chemotherapy. As shown in Figure 2, patients receiving a second-line treatment had a statistically significant $(P=0.0026$; long-rank test) longer median OS (12.7 months; $95 \%$ CI, 10.7-15.6)

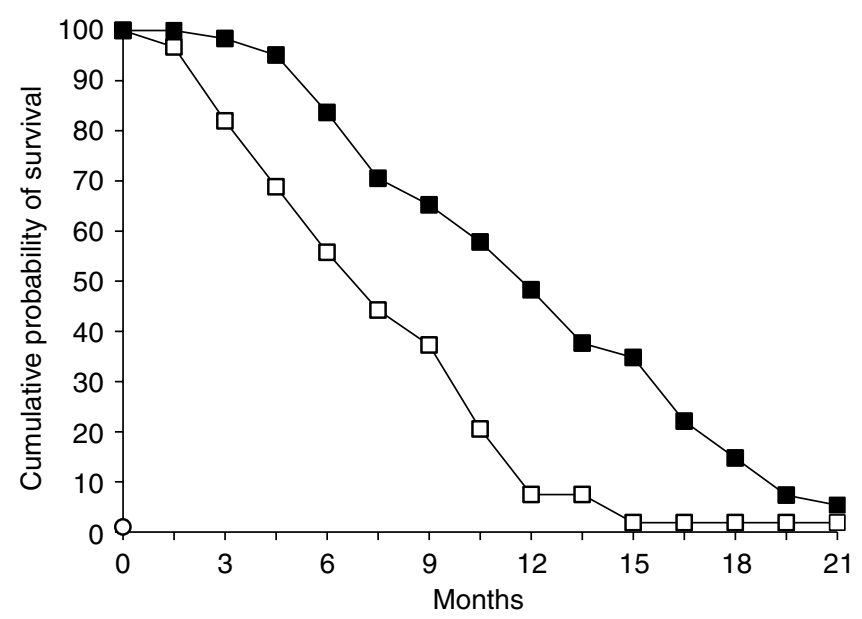

Figure I Estimated 21 -month cumulative probability of survival and time to treatment progression in 6I AGC patients. Shown are TTP $(\square \square \square \square \square \square$ ) and OS ( $\mathbf{\square} \mathbf{\square} \mathbf{~})$ in the 6I AGC patients treated with the FOLFOX-4 regimen.

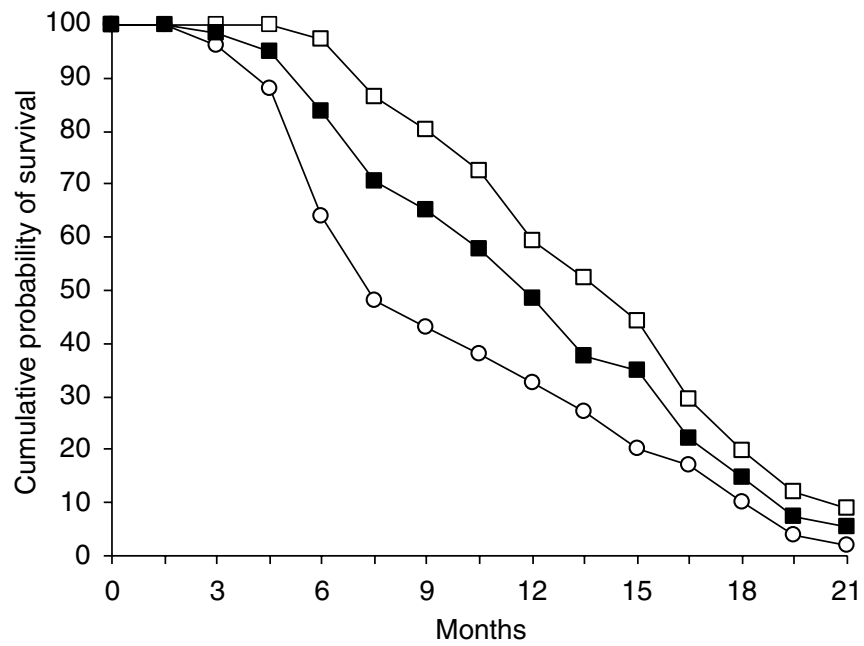

Figure 2 Estimated 21 -month cumulative probability of survival in 61 AGC patients. Shown are OS in the 36 AGC patients treated with secondline chemotherapy ( $\square \square \square \square \square \square$ ) and in the 25 patients treated with best supportive care $(\bigcirc \bigcirc \bigcirc \bigcirc \bigcirc)$ following disease progression. The figure also depicts OS in the 61 patients

than patients (25 patients) receiving only best supportive care (median OS, 9.4 months; 95\% CI, 5.6-12.7).

\section{Toxicity}

A total of 450 cycles were administered, with a median of seven cycles for patients (range, 3-15 cycles). A total of 45 out of 61 patients $(74 \%)$ received at least six cycles, 34 out of 61 patients (56\%) received at least eight cycles and 14 out of 61 patients $(23 \%)$ received at least 10 cycles. The occurrence and the incidence of main toxicities are reported in Table 2. The most common toxicities were haematologic. The National Cancer Institute Common Toxicity Criteria grade 3 and 4 neutropenia, leucopenia, 
anaemia and thrombocytopenia were recorded in 22 out of 61 $(36 \%), 11$ out of $61(16 \%)$, six out of $61(10 \%)$ and three out of 61 (5\%) patients, respectively. Three out of 61 patients experienced febrile neutropenia. No NCI-CTC grade 4 gastrointestinal toxicity was observed, while grade 3 diarrhoea, nausea and vomiting were recorded in 5,5 and $2 \%$ of the patients, respectively. Neurotoxicity was moderate and was observed in $30 \%$ (grade 1 in $11 \%$, grade 2 in $14 \%$ and grade 3 in 5\%) of the patients. The three patients who experienced a grade 3 neurotoxicity received a dose of oxaliplatin ranging from 935 to $1275 \mathrm{mg} \mathrm{m}^{-2}$ and cycles from 11 to 15 . Three patients $(5 \%)$ discontinued treatment because of treatment-related side effects, specifically neutropenia (one patient), diarrhoea (one patient) and neurotoxicity (one patient). No treatment-related death was reported.

Table 2 Main toxicities according to NCl-CTC scale

\begin{tabular}{lcc}
\hline Toxicity & Grade I - 2 (\%) & Grade 3-4 (\%) \\
\hline Haematologic & $14(23)$ & $22(36)$ \\
Neutropenia & $11(18)$ & $12(19)$ \\
Leucopenia & $20(32)$ & $3(5)$ \\
Thrombocytopenia & $23(37)$ & $6(10)$ \\
Anaemia & - & $2(3)$ \\
Febrile neutropenia & & $3(5)$ \\
Gastrointestinal & $13(21)$ & $1(2)$ \\
Nausea & $12(19)$ & $3(5)$ \\
Vomiting & $14(23)$ & $1(2)$ \\
Diarrhoea & $7(11)$ & - \\
Stomatitis & $1(2)$ & $3(5)$ \\
Hepatic & $16(26)$ & \\
Neurological & & \\
Others & $12(19)$ & - \\
Cutaneous & $13(21)$ & - \\
Alopecia & $2(3)$ & - \\
Asthenia & & - \\
Allergic & $(2)$ & \\
\hline Accordic & $(2)$ & \\
\hline
\end{tabular}

${ }^{a}$ According to an oxaliplatin-specific scale (grade $0-3$ ).

\section{DISCUSSION}

Although gastric cancer is considered a relatively chemotherapysensitive tumour with an overall response rate ranging between 30 and $60 \%$, survival of AGC patients remains unsatisfactory, with a median survival time of 6-9 months (Ho et al, 1988; Kelsen et al, 2002). None of the current regimens can be considered as an optimal therapy for AGC and new therapeutic strategies are needed to achieve a better clinical efficacy with an acceptable toxicity profile. In the present study, we administered the combination of FA, 5-FU and oxaliplatin as first-line therapy to patients with AGC. In all, 23 of $61(38 \%)$ patients achieved an objective response, with a 7\% CR rate. The overall median TTP was 7.14 months, with a median OS of 11.2 months. The results of this study confirm the activity of a biweekly FOLFOX-4 regimen in the first-line treatment of AGC patients. To our knowledge, this is the largest phase II study in this patient population. Indeed, the other two phase II trials of oxaliplatin, 5-FU and FA combination in chemotherapynaive AGC patients enrolled 54 (49 patients were assessable for response) and 41 (37 patients were assessable for response) patients, respectively (Louvet et al, 2002; Al-Batran et al, 2004). Table 3 summarises the results of our study in comparison with the two previously published phase II trials of oxaliplatin, FA and 5-FU as first-line therapy in AGC patients. RR was comparable in the three studies. However, the median TTP and OS in the present study were slightly better than those reported in the other two studies. The prolonged survival observed in our study cannot be related to a selected patient population with a good outcome, because 56 out of $61(92 \%)$ patients had a metastatic disease and $63 \%$ had at least two metastatic sites. On the contrary, it could be explained by the fact that $59 \%$ of the study population received a second-line therapy. In fact, the 36 patients receiving a second-line treatment with docetaxel or irinotecan had a significant better median OS than the 25 patients receiving only best supportive care (12.7 vs 9.4 months; $P=0.0026$ ). These data suggest that salvage chemotherapy in AGC patients progressing after a first-line treatment may have a beneficial impact on survival, as has also been shown in other reports (Ajani et al, 2002; Giuliani et al, 2003). As previously observed in advanced colorectal cancer, in AGC patients, the FOLFOX regimen used in this study demonstrated an acceptable tolerability. Grade $3 / 4$ neutropenia was the most

Table 3 Comparison of the published phase II studies using FOLFOX combinations as first-line chemotherapy in AGC patients

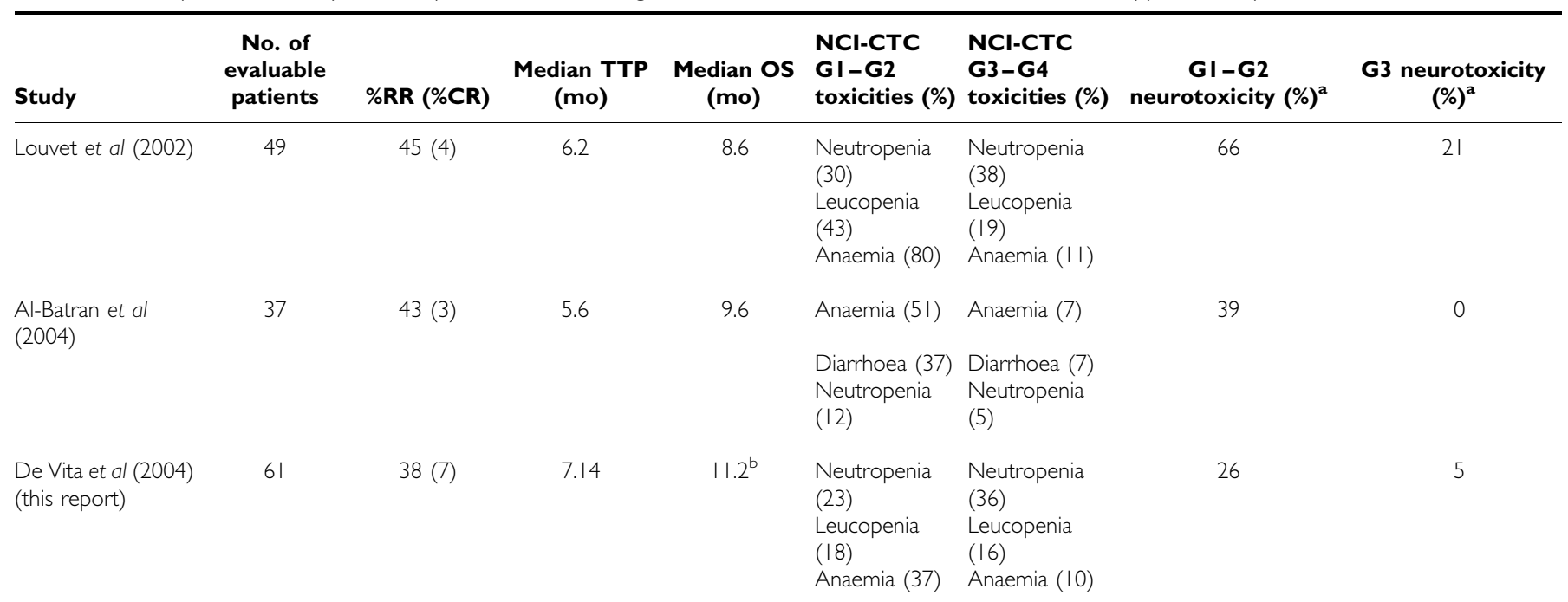

${ }^{a}$ According to an oxaliplatin-specific scale (grade $0-3$ ). ${ }^{b}$ Overall survival was 12.74 months in 36 out of 61 patients receiving a second-line chemotherapy and 9.46 months in 25 out of 61 patients treated with best supportive care following disease progression. $A G C=$ advanced gastric cancer; $C R=$ complete response; $T T P=$ time to progression; OS $=$ overall survival; $\mathrm{mo}=$ months. 
common haematologic toxicity occurring in $36 \%$ of the patients, but febrile neutropenia was detected in only $3 \%$ of the patients. In a number of trials with oxaliplatin-based therapies, neurotoxicity was the most frequent side effect that led to treatment discontinuation. However, in our study, neurotoxicity was restricted to a limited number of patients. This may be due to a relatively low cumulative dose of oxaliplatin in our series, with a median number of seven cycles administered. In particular, in the study by Louvet et al (2002), in which oxaliplatin was administered at a dose of $100 \mathrm{mg} \mathrm{m}^{-2}$, peripheral neuropathy was reported in $87 \%$ of the treated population and was severe (grade 3 toxicity) in $21 \%$ of the patients. In our series, diarrhoea, nausea and vomiting were the most common side effects among nonhaematologic toxicities, but were mild and occurred less frequently when compared with CDDP-based regimens such as FUP and ECF (Kim et al, 1993; Webb et al, 1997). Similarly, alopecia was a rare side effect when compared with anthracyclines or etoposide-based regimens. The efficacy of this FOLFOX treatment was not different from that observed in phase II-III studies with other second- or third-generation polychemotherapy regimens in AGC (Lacave et al, 1991; Wils et al, 1991; Kelsen et al, 1992; Kim et al 1993; Rougier et al, 1994; Vanhoefer et al, 2000). Interestingly, the median TTP and OS observed in our study population are similar to those reported in a prospectively randomised study comparing ECF with the standard regimen FAMTX (Webb et al, 1997). In conclusion, FOLFOX-4 treatment appears to have a significant activity as first-line treatment for AGC patients, with an encouraging response rate and a mild toxicity profile; therefore, on the basis of these results, a phase III study comparing FOLFOX$4 v s$ ECF should be performed.

\section{REFERENCES}

Al-Batran SE, Atmaka A, Hegewisc-Becker S, Jaeger D, Hahnfeld S, Rummel MJ, Seipelt G, Rost A, Orth J, Knuth A, Jaeger E (2004) Phase II trial of biweekly infusional fluorouracil, folinic acid and oxaliplatin in patients with advanced gastric cancer. J Clin Oncol 22: 658-663

Alberts SR, Cervantes A, Van de Velde CJH (2003) Gastric cancer: epidemiology, pathology and treatment. Ann Oncol 14(Suppl 2): ii31ii36

Ajani JA, Baker J, Pisters PW, Ho L, Mansfield PF, Feig BW, Charnsagavej C (2002) Irinotecan/cisplatin in advanced, treated gastric or gastroesophageal junction carcinoma. Oncology 16: 16-18

Becouarn Y, Agostini C, Trufflandier N, Boulanger V (2001) Oxaliplatin: available data in non-colorectal gastrointestinal malignancies. Crit Rev Oncol Hematol 40: 265-272

Blot WJ, Devesa SS, Kneller RW, Fraumeni Jr JR (1991) Rising incidence of adenocarcinoma of the esophagus and gastric cardia. JAMA 265: $1287-$ 1289

Caussanel JP, Levi F, Brienza S, Misset JL, Itrhaki M, Adam R, Milano G, Hequet B, Mathe G (1990) Phase I trial of 5-day continuous venous infusion of oxaliplatin at circadian rhythm modulated rate compared with constant rate. J Natl Cancer Inst 82: 1046-1050

De Gramont A, Figer A, Seymour M, Homerin M, Hmissi A, Cassidy J, Boni C, Cortes-Funes H, Cervantes A, Freyer G, Papamichael D, Le Bail N, Louvet C, Hendler D, de Braud F, Wilson C, Morvan F, Bonetti A (2000) Leucovorin and fluorouracil with or without oxaliplatin as first-line treatment in advanced colorectal cancer. J Clin Oncol 18: 2938-2947

Eriguchi M, Nonaka Y, Yanagie H, Yoshizaki I, Takeda V, Sekiguchi M (2003) A molecular biology study of anti-tumor mechanisms of anticancer agent oxaliplatin against established human gastric cancer cells lines. Biomed Pharmacother 57: 412-415

Extra JM, Espie M, Calvo F, Ferme C, Mignot L, Marty M (1990) Phase I study of oxaliplatin in advanced cancer. Cancer Chemother Pharmacol 25: $299-303$

Giuliani F, Gebbia V, De Vita F, Maiello E, Di Bisceglie M, Catalano G, Gebbia N, Colucci G (2003) Docetaxel as salvage therapy in advanced gastric cancer : a phase II study of Gruppo Oncologico Italia Meridionale (G.O.I.M.). Anticancer Res 23: 4219-4222

Glimelius B, Ekstrom K, Hoffman K, Graf W, Sjoden PO, Haglund U, Svensson C, Enander LK, Linne T, Sellstrom H, Heuman R (1997) Randomised comparison between chemotherapy plus best supportive care with best supportive care in advanced gastric cancer gastric cancer. Ann Oncol 8: $163-168$

Ho D (1988) Epidemiologic studies in gastric cancer. In Gastric Cancer Ho D (ed) pp 1-25. New York, NY: Churchill Livingstone

Kelsen DP, Atiq OT, Saltz L, Niedzwieckid D, Ginn D, Chapman D, Heelan $\mathrm{R}$, Lightdale C, Vinciguerra V, Brennan M (1992) FAMTX versus etoposide, doxorubicin, and cisplatin: a random assignment trial in gastric cancer. J Clin Oncol 10: $541-548$

Kelsen DP, Van De Velde CJH, Minsky BD (2002) Gastric cancer: clinical management. In Gastrointestinal Oncology: Principles and Practice Kelsen DP, Daly JM, Kern SE, Levin B, Tepper JE (eds) pp 383-422. Philadelphia, PA: Lippincott Williams \& Wilkins

Kim DY, Kim JH, Lee SH, Kim TY, Heo DS, Bang YJ, Kim NK (2003) Phase II study of oxaliplatin, 5-fluorouracil and leucovorin in previously

platinum-treated patients with advanced gastric cancer. Ann Oncol 14: $383-387$

Kim NK, Park YS, Heo DS, Suh C, Kim SY, Park KC, Kang YK, Shin DB, Kim HT, Kim HJ (1993) A phase III randomized study of 5-fluorouracil and cisplatin versus 5 -fluorouracil, doxorubicin and mitomycin $\mathrm{C}$ versus 5-fluorouracil alone in the treatment of advanced gastric cancer. Cancer 71: $3813-3818$

Lacave AJ, Baron FJ, Anton LM, Estrada E, De Sande LM, Palacio I, Esteban E, Gracia JM, Buesa JM, Fernandez OA (1991) Combination chemotherapy with cisplatin and 5-fluorouracil 5-day infusion in the therapy of advanced gastric cancer: a phase II trial. Ann Oncol 2: 751-754

Levi F, Misset JL, Brienza S, Adam R, Metzger G, Itzakhi M, Caussanel JP, Kunstlinger F, Lecouturier S, Descorps-Declere A (1992) A chronopharmacologic phase II clinical trial with 5-fluorouracil, folinic acid and oxaliplatin using an ambulatory multichannel programmable pump. Cancer 69: 893-900

Levi FA, Zidani R, Vannetzel JM, Perpoint B, Focan C, Faggiuolo R, Chollet P, Garufi C, Itzhaki M, Dogliotti L (1994) Chronomodulated versus fixed infusion rate delivery of ambulatory chemotherapy with oxaliplatin, fluorouracil and folinic acid (leucovorin) in patients with colorectal cancer metastases: a randomized multinstitutional trial. $J$ Natl Cancer Inst 86: $1608-1617$

Louvet C, Andre T, Tigaud JM, Gamelin E, Douillard JY, Brunet R, Francois E, Jacob JH, Levoir D, Taamma A, Rougier P, Cvitkovic E, de Gramont A (2002) Phase II study of oxaliplatin, fluorouracil and folinic acid in locally advanced or metastatic gastric cancer patients. J Clin Oncol 20: $4543-4548$

Murad AM, Santiago FF, Petroianu A, Rocha PR, Rodrigues MA, Rausch M (1993) Modified therapy with 5-fluorouracil, doxorubicin and methotrexate in advanced gastric cancer. Cancer 72: 37-41

Parkin DM (1998) Epidemiology of cancer global patterns and trends. Toxicol Lett 102: 227-234

Pyrhonen S, Kuitunen T, Nyandoto P, Kouri M (1995) Randomised comparison of fluorouracil, epidoxorubicin and methotrexate (FEMTX) plus supportive care with supportive care alone in patients with non resectable gastric cancer. Br J Cancer 71: 587-591

Raymond E, Chaney SG, Taamma A, Cvitkovic E (1998) Oxaliplatin: a review of preclinical and clinical studies. Ann Oncol 9: 1053-1071

Rougier P, Ducreuk M, Mahjoubi M, Pignon JP, Bellefolih S, Oliveica J, Bognel C, Lasser P, Ychou M, Elias D (1994) Efficacy of combined 5fluorouracil and cisplatinum in advanced gastric carcinomas. A phase II trial with prognostic factor analysis. Eur J Cancer 30: 1263-1269

Simon R (1989) Optimal two-stage designs for phase II clinical trials. Control Clin Trials 10: 1-13

Vanhoefer U, Rougier P, Wilke H, Ducreux MP, Lacave AJ, Van Cutsem E, Planker M, Santos JG, Piedbois P, Paillot B, Bodenstein H, Schmoll HJ, Bleiberg H, Nordlinger B, Couvreur ML, Baron B, Wils JA (2000) Final results of a randomized phase III trial of sequential high-dose methotrexate, fluorouracil and doxorubicin versus etoposide, leucovorin and fluorouracil versus infusional fluorouracil and cisplatin in advanced gastric cancer: a trial of the European Organization for Research and Treatment of Cancer Gastrointestinal Tract Cancer Cooperative Group. J Clin Oncol 18: 2648-2657 
Webb A, Cunningham D, Scarffe JH, Harper P, Norman A, Joffe JK, Hughes M, Mansi J, Findlay M, Hill A, Oates J, Nicolson M, Hickish T, O'Brien M, Iveson T, Watson M, Underhill C, Wardley A, Meehan M (1997) Randomized trial comparing epirubicin, cisplatin and fluorouracil versus fluorouracil, doxorubicin and methotrexate in advanced esophagogastric cancer. J Clin Oncol 15: 261-267
Wils JA, Klein HO, Wagener DJ, Bleiberg H, Reis H, Korsten F, Conroy T, Fickers M, Leyvraz S, Buyse M (1991) Sequential high dose metyhotrexate and fluorouracil combined with doxorubicin: a step ahead in the treatment of advanced gastric cancer: a trial of European Organization for Research and Treatment of Cancer of Gastrointestinal tract cooperative Group. J Clin Oncol 9: 927-931 